\title{
INVESTMENT AND $Q$ IN SPANISH MANUFACTURING FIRMS
}

\author{
César Alonso-Borrego and Samuel Bentolila*
}

\section{INTRODUCTION}

The $Q$ model, originally suggested by Tobin (1969) and rigorously derived by Hayashi (1982), is one of the most appealing theories of fixed capital investment. The model implies a relationship between a firm's rate of investment and the ratio of the value for the firm of an additional unit of capital to its replacement cost ('marginal' $Q$ ). If $Q$ is greater than unity, ${ }^{1}$ it is optimal for the firm to invest. Empirical testing of the model is subject to certain conditions under which $Q$, which is unobservable, is equal to an observable magnitude, 'average' $Q$, defined as the ratio of the market value of physical capital stock to its replacement cost.

The leading model in the empirical investment literature has been, however, not the $Q$ model but the neoclassical-cum-accelerator model, in which the rate of investment depends, essentially, on the user cost of capital and output changes. Both models stem from a general framework of optimisation of the present value of the firm's cash flow, under certain assumptions. In principle, the advantage of $Q$ is that it involves the stockmarket valuation of the firm's capital, hence explicitly incorporating agents' expectations about the future return on the firm's capital. Econometric research estimating investment $-Q$ equations with macroeconomic data (e.g. Clark, 1982) has, nonetheless, not been very successful. The main cause for this failure was initially thought to be the use of aggregate data: the theory provides a relationship between two ratios, which can hardly be linearly aggregated.

This, and the fact that the components of $Q$ lend themselves more readily to calculation at the micro level, led to the estimation of $Q$ equations with

\footnotetext{
* We wish to thank V. Aguirregabiria, M. Arellano, O. Bover, J. M. González-Páramo, J. Padilla, R. Repullo, V. Salas, two anonymous referees and the participants in a workshop at the Banco de España for their comments. Our thanks also to J. Pérez, whose encouragement led us to research in this area; to L. Villanueva and the staff of the Central de Balances del Banco de España, for their help in obtaining the data; and to J. Saurina, for his assistance in calculating certain series and his comments. The authors alone are responsible for remaining errors.

' A normalized $Q$ is normally used, so that the benchmark value is in fact zero (see Section II).
} 
data on individual firms, for Japan (e.g. Hoshi and Kashyap, 1990; Hayashi and Inoue, 1991), the United Kingdom (e.g. Blundell et al., 1992) and the United States (e.g. Schaller, 1990). The main results from this line of research, which are remarkably similar across countries, are that $Q$ is significantly correlated with investment but implied adjustment costs are too high, and that the residuals of investment- $Q$ equations are correlated, thereby seemingly pointing to specification problems. In some cases it has been found that this correlation might be compatible with the $Q$ model (Blundell et al., 1992) and also that part of such correlation seems attributable to the imposition of equal coefficients across firms with highly heterogeneous behaviour (Schaller, 1990).

That said, there still remains a basic problem revealed by the empirical testing of the model. While the theory implies that $Q$ should be a sufficient statistic for investment, a common empirical finding is that variables whose information should already be incorporated into $Q$ - essentially, the level of output/sales and financial variables - are significant when jointly included with $Q .{ }^{2}$ These results suggest that key assumptions in the simplest version of the model, like those of perfect financial markets and perfect competition in product markets, are incorrect. Thus researchers have recently started to relax those assumptions. For example, Schiantarelli and Georgoutsos (1990) and Bond and Meghir (1991) present and test $Q$ models with imperfect competition $^{3}$ and liquidity constraints, respectively.

In this paper we provide further international evidence on the validity of the $Q$ theory by estimating investment equations over $1985-87$ for a sample of 68 Spanish private industrial firms, which were quoted in the stock market and answered the survey of the Bank of Spain's Central Balance Sheet Office (Central de Balances del Banco de España).

Previous work estimating investment equations with Spanish micro data (e.g. Espitia, 1985, or Giner, 1993) has found $Q$ to be significant. Our first aim is thus to replicate this finding with a different data set.

Our second goal is to test the relevance of a firm's financial position to its investment decisions, in the context of investment- $Q$ equations. In this way we explore the robustness of the finding, by Mato (1988), that variables proxying for financial constraints suffered by Spanish firms have additional explanatory power, when included alongside with the usual variables of the neoclassical-cum-accelerator model (see Hernando and Vallés, 1992, as well). We also test, indirectly, for imperfect competition by including sales as a regressor in the investment equation.

Our main findings are that $Q$ is significant in the investment equation, but other variables proxying for liquidity constraints are also significant; that once those variables are included, sales (which we introduce to check for

\footnotetext{
2 The former variables are found to be significant by Schiantarelli and Georgoutsos (1990) and the latter by Fazzari $e t$ al. (1988).

${ }^{3}$ The existence of market power had already been taken into account in Hayashi (1982), but it had not been considered in most of the empirical literature.
} 
market power) are not significant; and lastly that the adjustment costs implied by our estimated parameters are lower, and thus more reasonable, than those found in the international empirical literature.

The paper is structured as follows. Section II presents the equation we estimate, sample descriptive statistics of investment, the capital stock and $Q$, and the methods used to compute these variables (with the Appendix providing further details). Section III presents the results of estimating an equation relating fixed capital investment to $Q$ and then to other variables, and discusses the results. Section IV draws our conclusions.

\section{THE MODEL AND THE DATA}

\section{The model}

The $Q$ model is well known, so its derivation need not be repeated here (see e.g. Hayashi, 1982). The simplest version of the model assumes that firms operate under perfect competition and maximise the expected value of its current and future discounted cash flow.

The first order condition for such problem under the assumptions that the production and investment adjustment costs functions are homogeneous of degree one, that the latter is quadratic and subject to stochastic shocks and that adjustment of other factors of production is costless, can be written as:

$$
I_{i l} / K_{i, t-1}=\alpha+\gamma_{i}+\beta Q_{i t}+v_{i i}
$$

where $i$ indexes firms, $t$ indexes time, $I$ is gross investment and $K$ is beginning-of-period capital stock. The interpretation of the parameters is revealed by the assumed adjustment cost function:

$$
C_{i l}\left(I_{i l} / K_{i, t-1}\right)=(2 \beta)^{-1}\left[\left(I_{i l} / K_{i, t-1}\right)-\left(\alpha+\gamma_{i}+v_{i t}\right)\right]^{2}
$$

i.e. there is a frictionless investment rate defined by three additive terms: a firm-invariant parameter, $\alpha$, and two idiosyncratic terms, one constant, $\gamma_{i}$, and the other stochastic, $v_{i t}$. The scale parameter $\beta$ is firm-invariant.

Lastly, the regressor in equation (1) is 'average', tax-adjusted $Q$, defined as:

$$
Q_{i t}=\frac{\left(1-h_{t}-\tau_{t} z_{t}\right) P_{k i t}}{\left(1-\tau_{t}\right) P_{i t}}\left(q_{i t}-1\right)=\frac{\left(1-h_{t}-\tau_{t} z_{t}\right) P_{k i t}}{\left(1-\tau_{t}\right) P_{i t}}\left(\frac{V_{i t}-\tau_{t} A_{i t}}{\left(1-h_{t}-\tau_{t} z_{t}\right) P_{k i t} K_{i t}}-1\right)
$$

where $V$ is the value of the firm, $P$ the firm's output price, $P_{k}$ the price of capital, $\tau$ the tax rate on corporate profits, $\tau A$ the present value of future depreciation tax allowances on formerly purchased but not yet fully depreciated capital goods, $h$ the unit investment tax credit, and $z$ the present value of depreciation tax allowances per unit of investment. The ratio $q$ is the average value of capital, which - under the above assumptions - is equal to the ratio of the marginal value of capital to its price (Hayashi, 1982). 


\section{Sample statistics and the construction of $Q$}

Our sample comprises a set of private industrial firms, ${ }^{4}$ which were quoted on the stock market in 1982-87 and which answered every year the survey of the Spanish Central Balance Sheet Office (CBSO). ${ }^{5}$ Computing $Q$ is difficult, because we need both to identify the account items associated with economic variables and to estimate the market values of the former from their book values. The details of this process are described in the Appendix; here we merely wish to highlight a few issues. ${ }^{6}$

First, while the stock market assesses all of a firm's assets, we are interested in investment on depreciable fixed capital only. Thus our measure of the value of capital ( $V$ in equation (3)), includes the firm's liabilities, net of the market value of non-depreciable fixed capital, i.e. land and inventories. From this we subtract the present value of future tax savings through depreciation allowances, using as discount factor a firm-specific interest rate, equal to the cost of the firm's borrowed funds. Similarly, the denominator of $q$ contains the replacement cost of depreciable fixed capital only. This is broken down into four types of assets (buildings, machinery, transport equipment and 'utility plants in service'), the market value of each being calculated with economic (instead of accounting) depreciation rates and own-price series.

Second, the criteria followed in these calculations are unavoidably arbitrary and open to criticism. Indeed, our empirical analysis is performed with a sample of 68 firms, whereas the original sample contained 82 firms. For the remaining 14 firms, these criteria yield values for the components of $Q$ that we consider to be atypical. Nevertheless, to check the robustness of our results, we re-ran the estimation with the total sample of 82 firms, not getting very different results. ${ }^{7}$

The descriptive statistics of $q$ and other variables are shown in Table 1. Attention is drawn to the high value of $q$ in 1983, especially when compared with that in 1984. This is probably due to an understatement of capital in 1982 , the year immediately prior to a tax-free revision of asset book values. Even so, the capital stock seems somewhat understated even in 1983. As from 1984, both the mean and the standard deviation of $q$ increase monotonically, the latter in a greater proportion. For most firms $q$ exceeds the unit value in 1986, though values much below and above unity do exist.

The third aspect worth noting is that, due to lack of data on asset sales, investment is measured by the change in the balance sheet stock of fixed

\footnotetext{
${ }^{+}$Non-industrial and public firms are excluded, their investment decisions being thought not to be well captured by the usual models.

${ }^{5}$ The calculations to match the stock-market value of each firm to its financial statements were made by the CBSO, to ensure confidentiality.

"Hoshi and Kashyap (1990) provide an excellent discussion of the problems entailed by constructing $Q$ with accounting data.

${ }^{7}$ They are presented in Alonso and Bentolila (1992).

${ }^{8}$ Since in our estimation we use data for $1985-87$, this affects the set of instruments but not the regressors.
} 
TABLE 1

Descriptive statistics*

\begin{tabular}{lrrrrr}
\hline Year & \multicolumn{1}{l}{1983} & \multicolumn{1}{l}{1984} & \multicolumn{1}{c}{1985} & \multicolumn{1}{l}{1986} & \multicolumn{1}{c}{1987} \\
\hline$q$ ratio: & & & & & \\
$\quad$ Mean & 0.93 & 0.84 & 0.98 & 1.32 & 1.43 \\
Standard deviation & 0.40 & 0.40 & 0.60 & 0.74 & 0.96 \\
$\quad$ Maximum & 2.40 & 2.51 & 3.18 & 3.38 & 4.18 \\
Minimum & 0.24 & 0.23 & 0.20 & 0.25 & 0.32 \\
$Q$ (regressor): & & & & & \\
$\quad$ Mean & -0.07 & -0.17 & -0.01 & 0.32 & 0.44 \\
$\quad$ Standard deviation & 0.43 & 0.41 & 0.60 & 0.75 & 0.99 \\
Gross investment & & 73.86 & 105.79 & 52.39 & 50.33 \\
Capital stock & 524.74 & 893.99 & $1,012.97$ & $1,073.06$ & $1,102.92$ \\
Investment rate & & 0.13 & 0.08 & 0.10 & 0.09 \\
Cash-flow rate & & 0.08 & 0.07 & 0.08 & 0.09 \\
Sales rate & & 1.38 & 1.26 & 1.27 & 1.27 \\
\hline
\end{tabular}

*Mean rates are unweighted. Gross investment and capital stock are in million dollars (at 1991 exchange rates).

Source: Bank of Spain's Central Balance Sheet Office survey and own computations.

capital. This differs from the measure in other studies using data sets where the actual flow of investment expenditure is recorded. These two measures may differ considerably, e.g. when asset revaluation occurs.

Table 1 shows that, contrary to $q$, the investment rate exhibits a decreasing path and also that this is not due to the way in which the capital stock is calculated, since gross investment (at book value) declines over time too. This dissimilar course is a forerunner of the difficulties we may encounter when attempting to estimate a relationship between the investment rate and $q$. On the other hand, the cash-flow and sales rates show increasing paths as from 1985.

\section{ESTIMATION RESULTS}

\section{Econometric issues}

We aim to test the first-order condition given by equation (1), i.e. that investment bears a contemporaneous relationship with $Q$, and that other variables whose information should already be incorporated into $Q$ are not significant in an investment equation containing $Q$. This differs from the estimation of a structural investment equation, which, in particular, would require an additional equation explaining $Q$. An alternative interpretation, proposed by Abel and Blanchard (1986), is that we are describing the correlations present in the data between variables of interest.

The estimation of equation (1) raises several econometric issues, of which we stress two. The first one is that $Q$ should be correlated with the shock in 
the equation (i.e. it is endogenous) ${ }^{9}$, the second is that $Q$ is likely to be measured with error (measurement of capital is difficult, valuation criteria are arbitrary, etc.).

Both issues suggest that $Q$ should be instrumented. On the one hand, endogeneity implies that it is very hard to find valid contemporaneous external instruments. In the context of panel data estimation, however, we can use lags of endogenous variables as instruments. Our instrumental variables (IV) estimation is done with the generalised method of moments (with the DPD program by Arellano and Bond, 1988). We use the optimal matrix of instruments, so that all right-hand-side variables dated $t-1$ and earlier are included (which means that the number of instruments for each cross section is different) and exploit all the linear moment restrictions implied by the model (Arellano and Bond, 1991). On the other hand, the measurement error problem implies that the validity of specific lags as instruments will depend on the actual structure of such error. We shall go back to these issues below.

The dependent variable is the investment rate, i.e. investment during the year divided by the capital stock at the beginning of the year. Another relevant issue is that the model posits a contemporaneous relationship between investment and $Q$. We do not have, however, continuous accounting data, but annual data. This suggests regressing yearly investment on an annual mean of $Q$ calculated as the weighted average of the beginning- and end-of-year $Q$ values. We prefer to use these two variables separately, to exploit the fact that the former (which we call 'contemporaneous $Q$ '), should be more immune to endogeneity bias than the latter ('leading $Q$ '), in the sense that it can be treated as predetermined.

We control partially for the presence of firm-specific adjustment costs by including sectoral dummies. ${ }^{10}$ Time dummies are also included in order to capture macroeconomic phenomena affecting all firms equally. Despite there being data for five years, the construction of the variables and the inclusion of lagged regressors reduce the estimation period to only three years, from 1985 to 1987.

\section{Estimation of the investment $-Q$ relationship}

We start by estimating the relationship in levels. Column (1) of Table 2 presents the ordinary least squares (OLS) estimation results. As explained above, potential endogeneity and/or measurement error imply that we should estimate by instrumental variables. Column (2) reveals, however, that the coefficient hardly changes when $Q$ is instrumented. This suggests that neither the measurement error bias nor the endogeneity bias is large, or else that they roughly cancel each other. We perform a couple of regressions aimed at informally sorting out these explanations.

\footnotetext{
${ }^{9}$ Shocks to the adjustment costs function will affect the value of the firm, which in turn will affect $Q$.

"The definition of the sectors appears in the Appendix.
} 
Estimation of the relationship between investment and $Q$

Dependent variable: Investment rate

\begin{tabular}{lcccc}
\hline & $\begin{array}{l}\text { OLS } \\
(I)\end{array}$ & $\begin{array}{l}I V \\
(2)\end{array}$ & $\begin{array}{l}\text { OLS } \\
(3)\end{array}$ & $\begin{array}{l}\text { IV } \\
\text { (4) }\end{array}$ \\
\hline$Q$ & 0.039 & 0.040 & & \\
& $(3.51)$ & $(3.29)$ & & \\
$Q_{+1}$ & & & 0.031 & 0.040 \\
& & & $(3.76)$ & $(3.87)$ \\
$m_{1}$ & 0.95 & 1.03 & 1.11 & 1.28 \\
$m_{2}$ & 1.20 & 1.11 & 0.78 & 0.57 \\
$W(J S)$ & 40.91 & 36.97 & 42.92 & 39.58 \\
$W(S D)$ & 22.08 & 25.51 & 25.93 & 22.47 \\
$S T$ & & 7.86 & & 8.35 \\
\hline
\end{tabular}

NOTE: Critical values $(95 \%$ level)

$W(J S): \chi^{2}(8)=15.5 . W(S D): \chi^{2}(7)=14.1 . S T: \chi^{2}(5)=11.1$.

1. All regressions include a constant and sectoral and time dummies. In column (4) of Table 3 sectoral dummies are absent.

2 . Coefficients are two-step robust estimates. Heteroskedasticity-consistent $t$-ratios are reported below the estimated coefficients.

3. Statistics:

$W()=$. Wald tests distributed as $\chi^{2}$, with degrees of freedom provided below the tables.

$W(J S)=$ joint significance of the overall regression.

$W(S D)=$ joint significance of sectoral dummies.

$S T=$ Sargan Test of overidentifying restrictions, asymptotically distributed as $\chi^{2}$.

$m_{1}$ and $m_{2}=$ first- and second-order serial correlation statistics asymptotically distributed as standard normal variates.

4. Instrument sets:

All regressions: a constant, sectoral and time dummies, and $Q$ dated at $t-1$ and earlier. In column (1) of Table 2 no instruments are used. In Table 3, CF/K dated at $t-1$ and earlier is included in all cases; $Y / K$ dated at $t-1$ and earlier is included in column (3); and both sectoral dummies and $Q$ dated at $t-1$ are excluded in column (4).

A first approximation to the size of the endogeneity bias is given by the comparison of the OLS coefficients of contemporaneous and leading $Q$, since the former should be less subject to this type of bias than the latter. Column (3) reveals that both coefficients are quite similar. Since positive correlation between investment and $Q$ is expected, finding a slightly lower coefficient on leading $Q$ may be taken as an indication that the endogeneity bias is small.

With regard to measurement error, it matters only if it is serially correlated, because then lagged $Q$ would not be a valid instrument. This is not supported by the Sargan statistic, which is clearly below the critical value; but this test may not have much power in view of the small sample size. An informal test relies on checking whether the Sargan statistic falls when the first lag of $Q$, say, is excluded from the instrument set. When we do this the coefficient on $Q$ changes little (it becomes 0.037) and the Sargan statistic is almost unchanged 
(7.59), but since now there are only two overidentifying restrictions, the validity of the instrument set is rejected. This is not very conclusive, but in any event there is no strong evidence of correlated measurement error. These results suggest that neither endogeneity nor measurement error cause a large bias, though we should be cautious given the small sample size.

The estimates in levels just presented would be inconsistent if there exist unobservable fixed effects correlated with $Q$. To evaluate the incidence of this problem, we also estimate in first differences. Differencing generates a moving average structure in the error term (assuming it to be serially uncorrelated in levels), which provides an additional reason to use the instrumental variables method. It turns out that the first-difference IV estimate is a statistically insignificant coefficient of 0.012 , which is clearly below the estimate in levels. " This suggests the presence of individual effects correlated with $Q$. But in such cases we should find significant first- and second-order correlation in the residuals in levels, which is not apparent in either column (1) or (2). In the following section, we argue that the disparity between the levels and differences estimates may not be due to fixed effects but to misspecification of the equation causing an omitted variable bias.

Before doing this we should make two points. The first one, derived from comparing columns (2) and (4), is that the estimated coefficient does not depend on using contemporaneous or leading $q$, a feature which will be useful later on. The second one is a feature common to all regressions in Table 2, i.e. the overall significance of the sectoral dummies which, in the context of the model, implies the heterogeneity of adjustment costs. Omission of those dummies would produce an inconsistent estimate of the $Q$ coefficient.

\section{Testing the $Q$ model}

We test the model by including additional variables other than $Q$, which according to the model - should not be significant. We select a variable seeking to capture liquidity constraints the firm may face: cash-flow or internal funds (CF), rescaled by the (beginning-of-period) capital stock. This choice is based on the usual finding that, for several reasons (e.g. asymmetry in the information available to the managers of the firm and potential creditors thereof), several sources of funds give rise to different costs, internal funds being the least costly and, therefore, preferred by firms. Column (1) of Table 3 shows that $\mathrm{CF} / \mathrm{K}$ (instrumented with lags) is very significant, while both the coefficient and the significance of $Q$ diminish. The same is true when leading $Q$ is the regressor (column (2)). We read these results as consistent with the presence of credit constraints or financial hierarchy.

\footnotetext{
"Comparison of columns (2) and (4) reveals virtually identical coefficients on contemporaneous and leading $Q$. In the first differences estimation we use leading $Q$, in order to employ all three cross-sections (and exclude the first lag of $Q$ from the instrument set). The OLS estimate in first differences is 0.010 , again insignificant.
} 
TABLE 3

$Q$-model tests

Dependent variable: Investment rate

\begin{tabular}{lcccc}
\hline & $\begin{array}{l}\text { Levels } \\
(1)\end{array}$ & $\begin{array}{l}\text { Levels } \\
(2)\end{array}$ & $\begin{array}{l}\text { Levels } \\
(3)\end{array}$ & $\begin{array}{l}\text { Differences } \\
\text { (4) }\end{array}$ \\
\hline$Q$ & 0.021 & & 0.035 & \\
$Q_{+1}$ & $(1.85)$ & & $(3.19)$ & \\
$C F / K$ & & 0.021 & & 0.027 \\
& 0.350 & $(2.58)$ & & $(1.06)$ \\
$Y / K$ & $(2.89)$ & $(2.52)$ & 0.363 & 0.387 \\
& & & $(2.73)$ & $(1.67)$ \\
$m_{1}$ & & & -0.001 & \\
$m_{2}$ & 0.36 & 0.48 & $(0.24)$ & \\
$W(J S)$ & 0.52 & 0.27 & 0.81 & -3.48 \\
$W(S D)$ & 49.73 & 50.76 & 0.81 & -1.45 \\
$S T$ & 24.96 & 23.68 & 22.18 & 3.44 \\
\hline
\end{tabular}

NOTE: See notes to Table 2.

Critical values:

$W(J S): \chi^{2}(9)=16.9$. In column $(3): \chi^{2}(10)=18.3$. In column $(4): \chi^{2}(2)=5.99$.

$W(S D): \chi^{2}(7)=14.1$.

$S T: \chi^{2}(10)=18.3$. In column $(3): \chi^{2}(15)=25$

$C F / K=$ cash-flow rate and $Y / K=$ sales rate (see text).

The rejection of the model might also arise from firms operating in imperfectly competitive markets. Schiantarelli and Georgoutsos (1990) formulate and estimate a $Q$ model under monopolistic competition. The appropriate regressors in their model are current and leading $Q$, leading investment and current debt and output. Given the small size of our data set, we do not attempt to test such a model. Alternatively, we test the simplest $Q$ model by including, as an additional regressor, sales rescaled by beginning-of-period capital $(Y / K)$. The result, shown in column (3), is surprising. Once $Q$ and $C F / K$ are included, sales are not significant. Moreover, this happens in all the alternative econometric specifications we have tried, whereby no estimation including sales as a regressor is presented hereafter. The sales variable may contain a sizeable measurement error, owing to the accounting distortions caused by the introduction of value added tax (VAT) in 1986 (see the Appendix). We should note, moreover, that sales are significant when $Q$ is included but internal funds are not included, seemingly indicating that both variables capture liquidity constraints, the latter more accurately.

For the reasons stated in the previous subsection, we also estimate in first differences. Given how little the estimated coefficients in levels depend on 
whether contemporaneous or leading $Q$ is used, we choose the latter in order to exploit all three cross sections. Column (4) shows that the results are similar to those in levels, but now the variables are not significant. The Sargan test is close to rejecting the validity of the instrument set.

In summary, adding cash-flow as a regressor yields two results. First, the coefficient of $Q$ is not too sensitive to whether estimation is performed in levels or first differences. ${ }^{12}$ And second, there is no trace of first or second order correlation in the residuals in either column (1) or (2). Both findings suggest that there is no obvious problem of correlation between fixed-effects and regressors. This may be taken as an indication that the disparity found in the previous section can be explained by an omitted variable bias. As a result, we infer that the equation including only $Q$ is misspecified, i.e. that the first order condition of the simplest $Q$ model is invalid.

Since we have found significantly different coefficients depending on whether or not a cash-flow variable is included in the regression, and given the small number of observations available, we think it safer to conclude that the coefficient of $Q$ is the investment equation lies between 0.02 and 0.04 .

\section{Further discussions of the results}

We also estimated a set of regressions trying to check the sensitivity of the estimates to the way the variables are defined. We tried using modified measures of internal funds (in which corporate taxes and dividends paid out from profits were subtracted) and of the market value of the capital stock (in which we do not take the 1983 book values as the market values, but estimate the average age of capital to adjust book values for inflation and depreciation). The qualitative results remain unchanged, so we do not present them here. ${ }^{13}$

It is interesting to compare our results with those found in previous work. The comparison is difficult for several reasons. Not all authors define fixed assets in the same way; for example, some of them include assets that we have excluded here, like land or inventories. Also, some authors use direct data on investment (net of asset sales), while we can only observe net changes in the book value of capital.

In any event, let us compare the estimated implicit adjustment costs. These can be retrieved by multiplying half of the inverse of the estimated $Q$ coefficient by the square of the difference between the investment rate and the rate at which no costs are borne (see equation (2)). Let us assume that this difference is 5 percent. ${ }^{14}$ Our estimates of $\beta$ (once $C F / K$ is included) range from 0.021 (levels) to 0.027 (differences), which imply marginal adjustment cost of 5 to 6 percent. These costs were 2 percent in a previous estimation

\footnotetext{
12 We cannot statistically reject the equality of the estimates in columns (2) and (4).

$1{ }^{13}$ The reader can find them in Alonso and Bentolila (1992).

${ }^{14}$ Namely, that the adjustment cost is $(1 / 2 \beta)(0.05)^{2}$.
} 
with Spanish panel data over the period $1963-88$, by Giner (1993). The two estimates are not strictly comparable for the kind of reasons mentioned above, but it is reasonable that his estimate is lower, since he includes inventories in the capital stock (which should have much lower adjustment costs).

Our estimate seems more reasonable than those found for other countries, which are normally too high, the reason being that our estimated regression coefficient is higher. For instance, the estimation by Hoshi and Kashyap (1990) with Japanese data of a $Q$ coefficient of 0.01 , which is the highest in the international empirical literature with panel data that we know of, implies marginal adjustment costs of 11 percent.

Do our results imply the rejection of the $Q$ model in the Spanish case? We believe so, at least in the model's simplest form, i.e. under the usual assumptions of perfect competition in goods markets, perfect capital markets, constant returns to scale and linearly homogeneous convex adjustment costs. But our answer needs to be qualified for a host of reasons briefly discussed below.

(a) The variable indicated by the model is the so-called marginal $Q$, whereas we use average $Q$. The set of assumptions required for both to coincide are barely likely to arise in reality, so that variables other than $Q$ may help explain investment. However, the only paper we know of which constructs an approximate measure of marginal $Q$ (Abel and Blanchard, 1986) obtains very similar results to those with average $Q$ (though with aggregate data).

(b) We use data on four types of capital goods and apply different price indices and depreciation rates for each. But we then compute the capital stock as the simple sum of the amounts of these types of assets. The theory of investment with multiple capital goods proves (Wildasin, 1984) that this approximation requires a very strong assumption: the separability of adjustment costs for different asset types. In its absence, the rate of investment should be measured by the rate of change of an aggregate index of the stocks of the different capital goods. Nonetheless, the use of this method for a sample of Japanese firms, in Hayashi and Inoue (1991), does not yield very different results from those obtained with the procedure we follow.

(c) In our measure of the firm's market value, we use the stock market valuation in a single day at the end of the fiscal year, which could contain a high level of noise. The results for other countries lead us to think, however, that a measure of $Q$ with a time-averaged stock market valuation would not radically alter our results.

(d) The estimation exercises in which we use the end-1987 $Q$ (i.e. those in which leading $Q$ is used) may be distorted by the stock market crash in October that year. The theory does not specify how firms should behave if they think the stock market price differs from that warranted by the fundamentals, due, for example, to the presence of bubbles. If they decide to disregard the former in favour of fundamentals, we would expect the $Q$ coefficients to fall at times of 'unwarranted' stock market surges (Hoshi and Kashyap, 1990, obtain such a result for Japan). In contrast, we do not find 
major differences between the coefficients estimated with beginning- and end-of-period $Q$.

\section{CONCLUSIONS}

In this paper we estimate Tobin's $Q$ for a set of 68 Spanish private industrial firms over the period 1983-87. We then estimate the relationship between the investment rate and $Q$, and test the prediction of the simplest $Q$ model, namely that $Q$ is a sufficient statistic for investment.

The paper makes three main points. The first is that $Q$ is significant in an equation for investment in fixed capital, thus confirming previous results by other authors for the Spanish case (Espitia, 1985, and Giner, 1993). The significance of $Q$, and specially the fact that the estimates of adjustment costs derived from our estimation are more reasonable than those found for other countries, may come as a surprise once we take into account the underdeveloped nature of the Spanish stock exchange. This market has traditionally been very small, with few firms accounting for a very large proportion of the trading volume, it operated with a periodic call or batch system in a "cry out' form and was 'particularly vulnerable to manipulation (...) with half of all orders placed through commercial banks which also have enormous holdings in industrial and service companies' (Rubio, 1990, p. 338). In these circumstances, the stock market is unlikely to provide a good estimate of the market values of firms and so we would not expect $Q$ to be strongly correlated with investment. We sympathise with this view, although it might be argued that mispricing need not be positively correlated with trading volume (due to the presence, e.g. of noise traders). ${ }^{15}$ The explanation of our relatively favourable results might lie in the important changes undergone by the Spanish stock exchange in the $1980 \mathrm{~s}$, when relatively large increases in trading volumes and foreign investment took place, making it a more transparent and efficient market (see Rubio, 1990). ${ }^{16}$

Our second contribution is to have found that the simplest version of the $Q$ model is rejected, owing to the significance of financial variables. The latter aspect confirms for Spain the results obtained for other countries (for instance, Blundell et al., 1992, for the United Kingdom, or Fazzari et al., 1988 , for the United States) and by other researchers for the Spanish case using neoclassical-cum-accelerator models (Mato, 1988, Hernando and Vallés, 1992). This suggests - albeit in the absence of a more structured theoretical framework - that Spanish firms face liquidity constraints, presumably due to imperfections in financial markets. These constraints may plausibly be more binding in a country, such as Spain, where financial markets are still insufficiently developed.

\footnotetext{
${ }^{15}$ This point was made by an anonymous referee.

${ }^{16}$ Although this would not explain the results of Giner (1993), which cover a much larger period. This author provides an alternative explanation relying on the idea that intangible capital (i.e. 'goodwill', etc.), which may affect $Q$ but not investment, would be less important in Spanish firms than abroad, causing a larger coefficient on $Q$ in Spain than in other countries.
} 
Thirdly, unlike the evidence for other countries, we find no additional explanatory power in a firm's sales once $Q$ and cash-flow are included. In principle, this should be interpreted as indicative of perfect competition in Spanish manufacturing. We are reluctant to advocate this interpretation for several reasons: we are not really testing the proper equation derived from $Q$ models with imperfect competition (cfr. Schiantarelli and Georgoutsos, 1990), there is some empirical evidence of oligopolistic behaviour in Spanish manufacturing (e.g. Mazón, 1992) and, lastly, there are problems in the measurement of sales in our sample due to the introduction of VAT in 1986.

Lastly, we believe that the main limitation of our analysis arises from the small number of cross sections and firms we draw on. The former circumscribes the validity of our results, insofar as the coefficients estimated may strongly depend on the aggregate shocks during the sample period. ${ }^{17}$ The importance of this problem can only be diminished with a long sample period. Furthermore, the limited number of firms means that our sample is not representative of most Spanish industrial firms; these, generally, do not have access to the stock market for fund-raising purposes. Only with time may both aspects be improved.

\section{Universidad Complutense and CEMFI, Madrid \\ CEMFI, Madrid}

Date of Receipt of Final Manuscript: July 1993

\section{REFERENCES}

Abel, A. and Blanchard, O. (1986). 'The present value of profits and cyclical movements of investment', Econometrica, Vol. 54, pp. 249-73.

Alonso, C. and Bentolila, S. (1992). 'The relationship between investment and Tobin's $Q$ in Spanish industrial firms', Banco de España Working Paper 9203.

Arellano, M. and Bond, S. (1988). 'Dynamic panel data estimation using DPD - A guide for users', Institute for Fiscal Studies, mimeo.

Arellano, M. and Bond, S. (1991). 'Some tests of specification for panel data: Monte Carlo evidence and an application to employment equations', Review of Economic Studies, Vol. 58,pp. 277-97.

Bond, S. and Meghir, C. (1991). 'Alternative representations of investment models and financial regimes', Institute for Fiscal Studies, mimeo.

Blundell, R., Bond, S., Devereux, M. and Schiantarelli, F. (1992). 'Investment and Tobin's $Q$. Evidence from company panel data', Journal of Econometrics, Vol. 51, pp. 233-57.

Clark, P. (1979). 'Investment in the 1970s: theory, performance and prediction', Brookings Papers on Economic Activity, no. 1, pp. 73-113.

\footnotetext{
${ }^{17}$ As shown by Deaton (1992, chapter 5) for the estimation of first-order conditions in consumption theory.
} 
Deaton, A. (1992). Understanding consumption, Clarendon Press, Oxford.

Espitia, M. (1985). 'Aplicaciones microeconómicas de la $q$ de Tobin', Universidad de Zaragoza, unpublished Ph.D. dissertation.

Fazzari, S., Hubbard, R. and Petersen, B. (1988). 'Financing constraints and corporate investment', Brookings Papers on Economic Activity, no. 1, pp. 141-206.

Giner, E. (1993). 'Inversión y ratio Q de Tobin: estudio empírico con datos empresariales españoles', in Dolado, J., Martin, C. and Romero, L. R. (eds.). La industria y el comportamiento de las empresas españolas: Ensayos en homenaje a Gonzalo Mato, Alianza Editorial, Madrid.

González-Páramo, J. M. (1991). 'Imposición personal e incentivos fiscales al ahorro en España', Banco de España, mimeo.

Hayashi, F. (1982). 'Tobin's marginal $q$ and average q: A neoclassical interpretation', Econometrica, Vol. 50, pp. 213-24.

Hayashi, F. and Inoue, T. (1991). 'The relation between firm growth and $q$ with multiple capital goods: theory and evidence from panel data on Japanese firms', Econometrica, Vol. 59, pp. 731-53.

Hernando, I. and Vallés, J. (1992). 'Inversión y restricciones financieras: evidencia en las empresas manufactureras españolas', Moneda y Crédito, no. 195, pp. 185-222.

Hoshi, T. and Kashyap, A. (1990). 'Evidence on $q$ and investment for Japanese Firms', Journal of Japanese and International Economies, Vol. 4, pp. 371-400.

Hulten, C. and Wykoff, F. (1981). 'The measurement of economic depreciation', in Hulten, C. (ed.), Depreciation, Inflation and the Taxation of Income from Capital, Urban Institute, Washington.

Lindenberg, E. and Ross, S. (1981). 'Tobin's $q$ ratio and Industrial Organization', Journal of Business, Vol. 54, pp. 1-32.

Mato, G. (1988). 'Investment demand at the firm level: The case of Spain', Recherches Economiques de Louvain, Vol. 54, pp. 325-36.

Mazón, C. (1992). 'Márgenes de beneficio, eficiencia y poder de mercado en las empresas españolas', Banco de España Working Paper 9204.

Rubio, G. (1990). 'The stock market in Spain: performance, structure, and the behaviour of asset prices', Finanzmarkt und Portfolio Management; Vol. 4, pp. 332-54.

Schaller, H. (1990). 'A re-examination of the $q$ theory of investment using U.S. firm data', Journal of Applied Econometrics, Vol. 5, pp. 309-25.

Schiantarelli, F. and Georgoutsos, D. (1990). 'Monopolistic competition and the $q$ theory of investment', European Economic Review, Vol. 34, pp. 1061-78.

Tobin, J. (1969). 'A General equilibrium approach to monetary theory', Journal of Money, Credit and Banking, Vol. 1, pp. 15-29.

Wildasin, D. (1984). 'The $q$ theory of investment with many capital goods', American Economic Review, Vol. 74, pp. 203-10.

\section{APPENDIX. DEFINITIONS OF VARIABLES}

A firm's average, tax-adjusted $q$ is given by:

$$
q_{t}=\left(V_{1}-\tau_{t} A_{t}\right) / \Sigma_{j=1}^{4}\left(1-h_{t}-\tau_{l} z_{t}^{j}\right) p_{k l}^{j} K_{t}^{j}
$$

where $V$ is the market value of the firm, i.e. the sum of net debt plus equity less land and inventories. Superscript $j$ denotes capital goods types. The 
variable $Q$ normalises and expresses $q$ in terms of the firm's product prices, $P$ (with weights $\omega$ explained below), i.e.:

$$
Q_{t}=\left(q_{t}-1\right)\left[\Sigma_{j=1}^{4}\left(1-h_{t}-\tau_{t} z_{t}^{j}\right) \omega_{t}^{j} P_{k t}^{j}\right] /\left[\left(1-\tau_{t}\right) P_{t}\right]
$$

The calculation of these variables was carried out as follows:

1. Equity. Number of shares times the stock market price in the year-end session. (Source: Official Bulletins of the Madrid, Barcelona and Bilbao Stock Exchanges, and Banco de Bilbao's Agenda Financiera).

2. Net debt. Difference between gross debt and financial assets. Debt includes reserves akin to debt, but excludes capital-equivalent ones. Gross debt at market value, $D$, is computed as: $D=D S B+\mu D L B$, with $D S B$ the book value of short-term debt, DLB that of medium- and long-term debt and $\mu$ a revaluation factor, equal to a calculated market value of debt (financial expenses divided by interest rate on electricity company bonds) divided by the book value of total debt. The same method is applied to financial assets, using the interest rate on government debt. For intangibles, we take the book value as market value.

3. Capital stock and investment. The survey breaks down the physical capital stock into four categories: (1) Buildings and other structures, (2) Utility plants in service, (3) Machinery, equipment and tools, (4) Transport equipment.

We use a LIFO-type recursive valuation formula, which requires an estimate of the market value in the first sample year. We take the 1983 book value as the market value in that year. From then on we update the market value of the capital stock $(K M)$ in the following way:

$$
K M_{t}^{j}=\left[K M_{t-1}^{j}\left(P_{k, t}^{j} / P_{k, t-1}^{j}\right)+G I_{t}^{j}\right]\left(1-\delta^{\prime}\right)
$$

which assumes that depreciation occurs, at rate $\delta$, at the end of the year and gross nominal investment, $G I$, at the beginning.

Rates of depreciation for all assets but (2) are calculated by weighting the dissaggregated estimates of economic depreciation rates by Hulten and Wykoff (1981) for the US, using as weights the inputs of capital goods in each sector according to the 1980 Spanish input-output tables. The latter are also used in the construction of price indices for the four types of capital goods, as weights of official capital goods price indices. Both calculations are done for each of the two-digit groups in the Spanish National Classification of Economic Activities (CNAE). ${ }^{18}$

Utility plants in service are combinations, for accounting purposes, of several types of capital goods (essentially machinery and buildings). In fact,

\footnotetext{
geneity.

${ }^{18}$ Except for sectors 151 and 152 , which have been kept separate because of their hetero-
} 
their accounting depreciation rates always lie in between the economic depreciation rates of those two types of assets, so we calculate their depreciation rate from the accounting rates, assuming straight-line depreciation, i.e.:

$$
\delta^{j}=(1 / 6) \sum_{t=1982}^{1987}\left(A D_{t}^{j} / K B_{t}^{j}\right) \quad(j=2)
$$

where $A D$ is the annual provision for depreciation and $K B$ the book value of capital. This should, of course, be thought of only as an approximation to the exponential depreciation rate.

As to investment, no data are available on sales of assets, so we approximate it by the change in book values:

$$
G I_{t}^{j}=K B_{t}^{j}-K B_{t-1}^{j}+A D_{t}^{j}
$$

4. Land. We follow the same procedure as for capital. No land price index is available, so we use the price index for buildings.

5. Inventories. The data contain no information on the inventory valuation methods applied by firms. We adopt the average pricing method of Lindenberg and Ross (1981), so that the market value of inventories, $X M$, is equal to:

$$
X M_{t}=X B_{t}\left[P_{x t} / \frac{1}{2}\left(P_{x t}+P_{x, t-1}\right)\right]
$$

where $X B$ and $P_{x}$ are, respectively, the book value and the price of inventories.

6. Tax adjustment. Tax rate $(\tau): 35$ percent of the tax base. Investment tax credit (h): 12 percent of the tax base for 1983-84, 15 percent as from 1985. Depreciation: We apply the depreciation system permitted by law providing the largest present value of tax allowances and then calculate (using the formulae in González-Páramo, 1991) the present values of current ànd future credits of investments made in the current and previous years. The discount rate is approximated by the cost of borrowed funds for each firm, i.e. the ratio of financial expenses to total debt.

7. Computation of $Q$ on the basis of $q$. To compute $Q, q$ is multiplied by the price of capital and divided by the firm's output price. The former is calculated by weighting, with weights $\omega$, the price indices of each type of capital good by the proportion they account for in the firm's total nominal capital stock:

$$
\omega_{\prime}^{j}=K B_{j} / \Sigma_{j=1}^{4} K B_{t}^{j}
$$

The firm's price index is found by weighting the industrial price indices of the types of goods produced by the firm (2-digit $C N A E$ classification) by their share in the firm's nominal sales in 1983. 
8. Internal finance and sales. Definitions: Internal finance $(C F)=$ Accounting profits (losses) + Depreciation provisions + Operating provisions + Bad debts written off + Other provisions + Deferred earnings. Sales: Before 1986 we do not know the amount of indirect taxation included in sales. Thus we are forced to use sales gross of taxes. The introduction of VAT in 1986 creates an artificial jump in the series because the VAT rates are higher than previous indirect tax rates.

9. Sectoral dummies (number of firms in parentheses). Energy (12), Water (2) - excluded from the regressions -, Steel (10), Construction materials, glass and ceramics (5), Chemicals (12), Non-ferrous metals (10), Food (6), Other (11). 